\title{
Pengaruh Kualitas Pelayanan Terhadap Kepuasan Nasabah Pada PT. Prudential Life Assurance Kota Makassar
}

\section{The Effect of Service Quality on Customer Satisfaction on PT. Prudential Life Assurance Makassar City}

\author{
Mutmainna ${ }^{1)}$, Tien Kumalasari ${ }^{1)}$, Asriany ${ }^{1)}$ \\ 1)Jurusan Agribisnis Politeknik Pertanian Negeri Pangkajene Kepulauan \\ Corresponding Author : mutmainna74@yahoo.co.id
}

Diterima Tanggal 26 Maret 2020, Disetujui Tanggal 08 April 2020

\begin{abstract}
Abstrak
Pentingnya rasa aman dan terjaminnya hidup di masa sekarang ini, menjadikan manfaat asuransi sangat penting dan besar artinya. Beberapa manfaat yang ditimbulkan jika kita memiliki asuransi antara lain : a) Asuransi dapat menaikkan efesiensi dan kegiatan perusahaan, b) Dapat memberikan rasa aman dan terjamin dalam menkjalankan usaha, c) Asuransi cenderung ke arah perkiraan penilaian biaya yang layak, d) Asuransi merupakan dasar pertimbangan pemberian suatu kredit, e) Asuransi dapat mengurangi timbulnya kerugian-kerugian, f) Asuransi merupakan alat untuk membentuk modal pendapatan atau harapan masa depan, dan g) Asuransi merupakan alat pembangunan. Tujuan penelitian ini adalah untuk mengetahui : 1) Kualitas pelayanan pada PT. Prudential Life Assurance Kota Makassar, 2) Kepuasan konsumen pada PT. Prudential Life Assurance Kota Makassar, 3) Pengaruh kualitas pelayanan secara simultan terhadap kepuasan konsumen pada $P T$. Prudential Life Assurance Kota Makassar. Metode penelitian yang digunakan adalah metode purposive atau metode penentuan lokasi secara langsung dengan pertimbangan bahwa Kota Makassar merupakan wilayah sentra konsumen atau nasabah PT. Prudential Life Assurance, sedangkan metode analisis data yang digunakan adalah analisis regresi linier berganda, dimana variabel bebasnya adalah reliability, assurance, tangibles, empaty, dan responsive sedangkan variabel terikatnya adalah kepuasan nasabah. Hasil penelitian menunjukkan bahwa indikator-indikator pada penelitian ini bersifat valid dan reliable. Pada uji hipotesis reability, assurance, tangibles, empaty dan responsive berpengaruh signifikan terhadap kepuasan konsumen. Berdasarkan hasil analisis regresi linier berganda, bahwa kualitas layanan yang terdiri dari reability, assurance, tangibles, empaty dan responsive memberikan nilai positif dan signifikan terhadap kepuasan nasabah. Artinya bahwa ke-5 indikator berpengaruh secara simultan terhadp kepuasan nasabah pada bisnis jasa asuransi PT. Prudential Life Assurance, Kota Makssar.
\end{abstract}

Kata Kunci : Reability, Assurance, Tangibles, Empaty dan Responsive, PT. Prudential Life Assurance

\begin{abstract}
Absrtact
The importance of a safe and secure live in the present, makes insurance benefits very impoertant and great significance. Some of the benefits incurred if we have insurance include: a) Insurance can increase the efficiency and activities of the company, b) Can provide a sense of security and security in running a business, c) Insurance tends towards estimating a reasonable cost assessment, d) Insurance is the basis consideration of the purchase of a credit, e) Insurance can reduce the incidence of losses, f) Insurance is a tool
\end{abstract}


for forming capital income or future expectations, and g) Insurance is a development tool. The purpose of this study was to determine: 1) The quality of service at PT. Prudential Life Assurance Makassar City, 2) Consumer satisfaction at PT. Prudential Life Assurance Makassar City, 3) The effect of simultaneous service quality on customer satisfaction at $P T$. Prudential Life Assurance Makassar City. The research method used is a purposive method or the method of determining the location directly with the consideration that the City of Makassar is a consumer or customer center area of PT. Prudential Life Assurance, while the data analysis method used is multiple linear regression analysis, where the independent variables are reliability, assurance, tangibles, empathy and responsiveness while the dependent variable is customer satisfaction. The results showed that the indicators in this study are valid and reliable. In the hypothesis testing reability, assurance, tangibles, empathy and responsiveness have a significant effect on customer satisfaction. Based on the results of multiple linear regression analysis, that reliability, assurance, tangibles, empathy and responsiveness provide a positive and significant value of service quality to customer satisfaction. This means that the 5 indicators simultaneously influence consumer satisfaction in the insurance service business of PT. Prudential Life Assurance Makassar City.

Key Words Reability, Assurance, Tangibles, Empaty dan Responsive, PT. Prudential Life Assurance

\section{PENDAHULUAN}

Asuransi atau alat pertanggungan merupakan sesuatu yang sudah tidak asing lagi bagi masyarakat Indonesia, dimana sebagian besar masyarakat Indonesia sudah melakukan perjanjian asuransi dengan perusahaan asuransi, baik perusahaan asuransi milik negara maupun milik swasta (Purwosutjipto, 2016).

Perusahaan Asuransi PT. Prudential Life Assurance Indonesia merupakan penyedia jasan asuransi jiwa dan merupakan bagian dari Prudencial plc. Sebuah group perusahaan jasa keuangan terkemuka di Inggris. Sejak meluncurkan produk asuransi jiwa yang dikaitkan dengan investasi (unit link) pertamanya di tahun 1999, Prudential Indonesia merupakan pimpinan pasar untuk produk tersebut di Indonesia. Prudential Indonesia merupakan pemimpin pasar untuk produk tersebut di Indonesia. Prudential Indonesia telah mendirikan unit bisnis syariah sejak tahun 2007 dan dipercaya sebagai pemimpin pasar asuransi jiwa syariah sejak pendiriannya di Indonesia.

Kota Makassar sebagai salah satu kota besar yang menjadi Kantor Pemasaran Mandiri (KPM) sejak tahun 2010 dan memiliki wilayah pemasaran sebanyak 10 Kantor Pemasaran yang disebut dengan MK. Hal ini menunjukkan bahwa PT. Prudential Life Assurance wilayah Makassar telah dipercaya sebagai perusahaan jasa asuransi yang dapat memberikan perlindungan asuransi jiwa dan beragam asuransi tambahan sesuai dengan kebutuhan nasabah (www.prudential.co.id).

Kesadaran masyarakat Kota Makassar dalam perlindungan kesehatan dan pendidikan, menjadikan perusahaanperusahaan asuransi Jiwa dan Pendidikan semakin bertambah disertai dengan pertambahan jumlah nasabah atau konsumen dari perusahaan asuransi seperti PT. Prudential Life Assurance. Agen-agen $\quad P T$. Prudential Life Assurance wilayah Makassar harus selalu memberikan informasi dan pelayanan yang cepat apabila ada nasabah yang klaim terhadap asuransinya.

Berdasarkan hal tersebut, perlu dilakukan penelitian dengan judul Pengaruh Kualitas Pelayanan Terhadap Kepuasan Konsumen pada PT. Prudential Life Assurance Kota Makassar. Penelitian ini bertujuan mengetahui :

a) Gambaran karateristik nasabah PT. Prudential Life Assurance Kota Makassar; 
b) Kualitas pelayanan pada $P T$. Prudential Life Assurance Kota Makassar; dan

c) Pengaruh kualitas pelayanan secara simultan terhadap kepuasan konsumen (nasabah) pada PT. Prudential Life Assurance Kota Makassar.

Hasil penelitian dapat dijadikan sebagai bahan masukan yang cepat dan akurat untuk merumuskan kebijakan pengembangan perusahaan jasa seperti

Penelitian ini dilaksanakan selama 8 (delapan) bulan dimulai pada April sampai November 2019 dengan lokasi penelitian di Kota Makassar. Daerah Penelitian ditentukan secara purposive atau secara sengaja dengan pertimbangan bahwa Kota Makassar merupakan wilayah sentra nasabah dari PT. Prudential Life Assurance.

\section{Teknik Pengumpulan, Jenis dan Sumber Data}

Teknik pengumpulan data yang dipergunakan dalam penelitian ini adalah : dokumentasi, interview dan observasi (Siyoto, 2015). Jenis data merupakan data kuantitatif. Data yang dikumpulkan meliputi data primer dan data sekunder. Data primer yang dikumpulkan diantaranya data Reliability $\left(X_{1}\right)$, Assurance $\left(X_{2}\right)$, Tangible $\left(X_{3}\right)$, Empaty $\left(X_{4}\right)$, dan Responsivess $\left(X_{5}\right)$. Data sekunder dikumpulkan dari berbagai sumber yang berhubungan dengan penelitian diantaranya BPS, Dinas Ketenagakerjaan, dan sumber lain yang berkaitan dengan kepuasan konsumen atau nasabah.

\section{Metode Pengambilan Sampel}

Metode pengambilan sampel dalam penelitian ini adalah :

1. Sampel lokasi, metode yang digunakan adalah purposive dengan pertimbangan bahwa Kota Makassar perusahaan asuransi di Kota Makassar dan Memberikan bahan informasi objektif bagi masyarakat luas untuk mendapatkan informasi tentang pentingnya berasuransi, manfaat asuransi yang bukan hanya perlindungan terhadap jiwa atau kesehatan tetapi juga untuk masa depan keluarga misalnya pendidikan.

\section{METODE}

\section{Waktu dan Lokasi Penelitian}

merupakan wilayah yang banyak masyarakat menjadi nasabah dari PT. Prudential Life Assurance.

2. Sampel yang digunakan dalam penelitian ini adalah konsumen atau nasabah yang menggunakan jasa asuransi PT. Prudential Life Assurance Kota Makassar atau MK 3 yang masih aktif dalam periode 1 Januari 2018 hingga 1 April 2019. Namun pihak perusahaan tidak dapat memberikan data nasabah secara rinci untuk penelitian ini dikarenakan alasan rahasia perusahaan.

3. Jumlah populasi konsumen atau nasabah yang menggunakan jasa asuransi PT. Prudential Life Assurance Kota Makassar atau MK 3 sebanyak 873 nasabah. Metode pengambilan sampel menggunakan metode acak sederhana (Simple Random Sampling) dimana setiap anggota populasi memiliki peluang yang sama untuk dijadikan sampel karena populasi tersebut (Nasabah Prudential) dianggap homogen (Sugiyono, 2001). Berdasarkan persentasi kelonggaran ketidatelitian karena kesalahan pengambilan sampel sebesar 10\% maka jumlah sampel sebanyak 87 nasabah (Margono, 2004).

\section{Metode Analisis Data}

Metode analisis data yang digunakan dalam penelitian ini yaitu :

1. Analisis Deskriptif, digunakan untuk menganalisis responden tentang Kualitas Pelayanan dan Kepuasan 
Pelanggan/Nasabah pada PT. Prudential Life Assurance Kota Makassar (MK 2) . Skala yang dipakai untuk mengetahui kepuasan pelanggan dari segi kualitas pelayanan jasa yang telah diberikan adalah skala likert yang terdiri dari: sangat baik, baik, cukup, tidak baik, sangat tidak baik. Kelima penilaian berikut diberi bobot sebagai berikut:

\begin{tabular}{|c|c|c|}
\hline No. & Penilaian & Skala \\
\hline 1. & $\begin{array}{c}\text { Sangat Setuju } \\
(\text { SS) }\end{array}$ & 5 \\
\hline 2. & Setuju (S) & 4 \\
\hline 3. & $\begin{array}{c}\text { Kurang Setuju } \\
\text { (KS) }\end{array}$ & 3 \\
\hline 4. & Tidak Setuju (TS) & 2 \\
\hline 5. & $\begin{array}{c}\text { Sangat Tidak } \\
\text { Setuju (STS) }\end{array}$ & 1 \\
\hline
\end{tabular}

2. Analisis Regresi Linier Berganda digunakan untuk menganalisis pengaruh kualitas pelayanan terhadap kepuasan pelanggan/nasabah baik secara simultan maupun parsial.

Persamaan regresi yang digunakan adalah sebagai berikut :

$\mathbf{Y}=\mathbf{a}+\mathbf{b}_{1} \mathbf{X}_{1}+\mathbf{b}_{2} \mathbf{X}_{2}+\mathbf{b}_{3} \mathbf{X}_{3}+\mathbf{b}_{4} \mathbf{X}_{4}+$ $b_{5} X_{5}$

3. Analisis Koefesien Determinan $\left(\mathrm{R}^{2}\right)$

Digunakan untuk mengukur seberapa jauh kemampuan model dalam menerangkan variasi variabel dependen (Kepuasan Pelanggan). Nilai koefesien determinasi adalah antara nol dan satu. Nilai koefesien determinasi yang kecil berarti kemampuan variabel-variabel indevenden (kualitas pelayanan) dalam menjelaskan variabel dependen (kepuasan pelanggan) amat terbatas. Nilai koefesien determinasi yang mendekati satu berarti variabel-variabel independen (kualitas pelayanan) memberikan hamper semua informasi yang dibutuhkan untuk memprediksi variasi variabel dependen (kepuasan pelanggan).

\section{HASIL DAN PEMBAHASAN}

\section{A. Gambaran Umum Nasabah}

Nasabah merupakan peserta asuransi pada PT. Prudential Life Assurance Kota Makassar yang telah menjadi nasabah selama \pm 2 tahun. Berdasarkan hasil penyebaran kuesioner yang telah dilakukan kepada 87 orang nasabah PT. Prudential Life Assurance, maka peneliti membagi karateristik nasabah menjadi 4 bagian yaitu :

a) Deskripsi nasabah berdasarkan jenis kelamin, dimana hasil menunjukkan bahwa nasabah perempuan lebih banyak yakni sebanyak 60 orang (68.97\%). Hal ini disebabkan karena minat perempuan untuk menggunakan jasa asuransi PT. Prudential Life Assurance Kota Makassar lebih besar dibanding laki-laki dan berdasarkan hasil wawancara bahwa keputusan perempuan untuk menjadi nasabah asuransi dilatarbelakangi oleh pengaturan keuangan dan ketakutan akan musibah atau kecelakaan lebih banyak dilakukan oleh perempuan;

b) Deskripsi nasabah berdasarkan umur, dimana hasil analisis menunjukkan bahwa umur 31 - 40 tahun lebih banyak menjadi anggota asuransi yakni sebanyak 33 orang (37.93\%). Hal ini disebabkan nasabah yang berumur antara 31 - 40 tahun telah memiliki banyak pengetahuan tentang asuransi, rajin membaca dan mencari informasi tentang pentingnya asuransi sehingga keputusan untuk mengikuti asuransi khususnya asuransi kesehatan/jiwa dan pendidikan contohnya PT. Prudential Life Assurance Kota Makassar lebih mudah dan cepat;

c) Deskripsi nasabah berdasarkan pendidikan terakhir, dimana hasil analisis menunjukkan bahwa nasabah yang terbanyak menjadi anggota asuransi adalah nasabah yang berpendidikan sarjana yakni sebanyak 29 orang atau 33.33\%. Hal disebabkan karena nasabah yang memiliki tingkat pendidikan sarjana telah memiliki banyak pengalaman, 
tingkat kehidupan ekonomi dan keuangan lebih baik serta pengetahuan tentang manfaat asuransi lebih banyak;

d) Deskripsi nasabah berdasarkan pekerjaan, dimana nasabah $P T$. Prudential Life Assurance Kota Makassar yang terbanyak adalah pengusaha. Hal ini dapat dilihat dari jumlah nasabah sebanyak 39 orang $(44.83 \%)$.

\section{B. Tingkat Kualitas Pelayanan PT. Prudential Life Assurance Kota Makassar (MK 3)}

Tingkat kualitas pelayanan yang diberikan oleh PT. Prudential Life Assurance Kota Makassar menggunakan skala likert. Pengukuran ini berdasarkan pada kondisi objek dalam menentukan keputusan terhadap suatu pilihan dengan indikator penguluran yaitu Sangat Setuju (SS) dengan bobot penilaian sebesar 5, Setuju (S) dengan bobot penilaian sebesar 4, Kurang Setuju (KS) dengan bobot penilaian sebesar 3, Tidak Setuju (TS) dengan bobot penilaian sebesar 2 dan Sangat Tidak Setuju dengan bobot penilaian 1.

Hasil analisis tentang kualitas dan kepuasan nasabah asuransi $P T$. Prudential Life Assurance Kota Makassar dapat dilihat melalui deksripsi variabel kualitas pelayanan yakni Relialibility, Assurance, Tangibel, Empathy, dan Responsiveness, , serta Kepuasan Pelanggan $(\mathrm{Y})$ itu sendiri.

Bentuk pelayanan yang diberikan oleh perusahaan melalui pengukuran variabel reliability $(\mathrm{Rb})$ tentang kehandalan, dimana 58 orang nasabah (67\%) memilih setuju terhadap kemampuan agen untuk menyimpan identitas rahasia nasabah. Hal ini dikarenakan, nasabah ataupun calon nasabah akan merasa aman dan nyaman apabila seluruh identitas pribadi dapat dirahasiakan oleh PT. Prudential Life Assurance Kota Makassar.

Bentuk pelayanan yang diberikan oleh perusahaan melalui pengukuran variabel Assurance (Ar) tentang jaminan yang diberikan oleh perusahaan, dimana sebesar 67 orang nasabah (77\%) memilih setuju terhadap agen PT. Prudential Life Assurance Kota Makassar dapat diandalkan dan bersifat professional kepada nasabah/calon nasabah. Hal ini dikarenakan, setiap agen diberikan pelatihan pemasaran dan kemampuan untuk negosiasi serta memupuk kepribadian melalui pelatohan customer service sehingga dapat memberikan pelayanan yang baik dan memuaskan kepada nasabah atau calon nasabah PT. Prudential Life Assurance Kota Makassar

Bentuk pelayanan yang diberikan oleh perusahaan melalui pengukuran variabel Tangible (Tb) sebesar 57 orang nasabah $(66 \%)$ memilih setuju terhadap agen yang senantiasa memperkenalkan dan menjelaskan fasilitas yang dimiliki perusahaan. Hal ini menunjukkan bahwa ketertarikan seorang calon nasabah atau nasabah terhadap asuransi adalah penjelasan mengenai asuransi dan manfaat asuransi terhadap calon/nasabah itu sendiri dan agen harus selalu memberikan informasi tentang fasilitas perusahaan asuransi yang terbaik dan terlengkap agar calon/nasabah tidak raguragu untuk memilihi perusahaan asuransi seperti PT. Prudential Life Assurance Kota Makassar.

Bentuk pelayanan yang diberikan oleh perusahaan melalui pengukuran variabel Empathy (Ep) tentang empati seorang agen asuransi, dimana sebesar 87 orang nasabah $(100 \%)$ yang memilih tidak setuju terhadap agen yang membeda-bedakan status sosial dalam pelayanan terhadap nasabah atau calon nasabah. Hal ini disebabkan karena setiap agen sudah dilatih untuk selalu menghormati dan menghargai setiap nasabah atau calon nasabah. Tidak ada perbedaan dalam pelayanan untuk menjadi peserta suransi di PT. Prudential Life Assurance Kota Makassar.

Bentuk pelayanan yang diberikan oleh perusahaan melalui pengukuran variabel responsiveness $(\mathrm{Rp})$ tentang daya tanggap, dimana sebesar 68 orang nasabah $(78 \%)$ memilih setuju terhadap kemampuan agen untuk memberikan informasi yang jelas dan tepat. Hal ini dikarenakan, nasabah ataupun calon 
nasabah memerlukan informasi yang lengkap dan transparan mengenai hal-hal yang terkait auransi dan pertanggungan yang diberikan oleh nasabah.

Bentuk pelayanan yang diberikan oleh perusahaan melalui pengukuran variabel Kepuasan Nasabah Asuransi (KNA) tentang kepuasan nasabah menjadi anggota asuransi PT. Prudential Life Assurance Kota Makassar. Hasil analisis menunjukkan bahwa sebanyak 61 orang nasabah (70\%) yang memilih setuju, dimana agen selalu memberika rasa nyaman atas keramahan dan etika dari agen ketika melayani mereka. Hal ini disebabkan karena setiap agen berusaha untuk memberikan pelayanan yang terbaik bagi nasabah ataupun calon nasabah sebab PT. Prudential Life Assurance Kota Makassar memiliki slogan untuk memberikan perlindungan yang terbaik.

\section{Pengaruh Kualitas Pelayanan Secara Simultan Terhadap Kepuasan Nasabah pada PT. Prudential Life Assurance Kota Makassar}

Nasabah dalam memilih asuransi memiliki banyak pertimbangan dan pemikiran sebelum memutuskan produk asuransi yang mana cocok untuk dipilih. Pemilihan produk asuransi terkait dengan pelayanan yang diberikan oleh pihak $P T$. Prudential Life Assurance Kota Makassar melalui agen sebagai perpanjangan tangan dari perusahaan. Untuk mengetahui pengaruh kualitas pelayanan secara simultan terhadap kepuasan nasabah pada PT. Prudential Life Assurance Kota Makassar dapat diketahui dengan menggunakan analisis regresi linier berganda, dimana dalam penelitian ini menggunakan aplikasi software SPSS Statistics versi 20 bentuk persamaannya adalah :

\section{$Y=8.325+0.506 X_{1}+0.233 X_{2}+0.099 X_{3}+$ $0.110 X_{4}+0.035 X_{5}+\varepsilon$}

Maka berdasarkan hasil analisis dengan menggunakan program SPSS dapat dilihat pada tabel berikut :
a. Reliability
atau kehandalan
berpengaruh
signifikan

kepuasan nasabah akan pelayanan yang diberikan oleh jasa asuransi $P T$. Prudential Life Assurance Kota Makassar. Hal ini terlihat dari thitung $>$ $t_{\text {tabel }}$ sebesar 4,357 > 1,99. Besar pengaruh kehandalan terhadap kepuasan nasabah adalah $57 \%$.

b. Assurance atau jaminan yang diberikan oleh PT. Prudential Life Assurance Kota Makassar tidak berpengaruh signifikan terhadap kepuasan nasabah pada produk asuransi PT. Prudential Life Assurance Kota Makassar dengan $t_{\text {thitung }}<t_{\text {tabel }}$ sebesar 1,935 < 1,99. Besar pengaruh kehandalan terhadap kepuasan nasabah adalah $38 \%$.

c. Tangible atau bukti fisik tidak berpengaruh signifikan terhadap kepuasan nasabah akan pelayanan asuransi yang diberikan oleh agen. $\mathrm{Hal}$ ini terlihat dari $\mathrm{t}_{\text {hitung }}<\mathrm{t}_{\text {tabel }}$ sebesar $1,201<1,99$. Besar pengaruh bukti fisik terhadap kepuasan nasabah adalah 9,3\%. Hal ini berarti bukti fisik seperti dokumen-dokumen asuransi memiliki pengaruh namun tidak signifikan terhadap kepuasan nasabah.

d. Empathy atau empati tidak berpengaruh signifikan terhadap kepuasan nasabah akan pelayanan yang diberikan oleh agen $P T$. Prudential Life Assurance Kota Makassar dengan dengan $t_{\text {hitung }}<t_{\text {tabel }}$ sebesar 1,235 < 1,99. Besar pengaruh kehandalan terhadap kepuasan nasabah adalah $15 \%$.

e. Responsiveness atau daya tanggap berarah negatif dan tidak berpengaruh signifikan terhadap kepuasan nasabah akan pelayanan yang diberikan oleh agen PT. Prudential Life Assurance Kota Makassar dengan thitung $<t_{\text {tabel }}$ sebesar $-0,279<$ 1,99. Besar pengaruh daya tanggap terhadap kepuasan nasabah adalah $3,8 \%$.

Berdasarkan hasil analisis regresi berganda dengan menggunakan $P T$. Prudential Life Assurance Kota Makassar dapat diketahui dengan menggunakan analisis regresi linier berganda dengan 
menggunakan aplikasi software SPSS Statistics versi 20 bentuk persamaannya. Berdasarkan hasil pengujian statistik (Uji Anova/Uji F) dapat jelaskan bahwa variabel nilai $F=23,197$ dengan tingkat probability $0,000<0,05$ sehingga akan dibandingkan dengan besarnya $F_{\text {hitung, }}$ dengan $\mathrm{F}_{\text {tabel }}$ yang diperoleh melalui rumus $\mathrm{k} ; \mathrm{n}-\mathrm{k}$, sehingga diperoleh $\mathrm{F}_{\text {tabel }}$ sebesar $5 ; 87-5=5 ; 82$. Kemudian dicari pada distribusi nilai $F$ tabel dan ditemukan sebesar 2,33, karena nilai $F_{\text {hitung }} 23,197$ > 2,33 ( $\left.F_{\text {tabel }}\right)$ maka dapat ditarik kesimpulan bahwa vaiabel bebas $X_{1}, X_{2}, X_{3}, X_{4}$ dan $X_{5}$ secara simultan berpengaruh terhadap variabel terikat $(\mathrm{Y})$.

Uji koefisien determinan dilakukan untuk melihat besarnya pengaruh variabel tangible, reliability, responsiveness, assurance, dan emphaty terhadap kepuasan nasabah asuransi terhadap pelayanan PT. Prudential Life Assurance Kota Makassar. Berdasarkan hasil analisis dapat dijelaskan bahwa $R^{2}=$ 0,658 yang berarti besarnya pengaruh tangible, reliability, responsiveness, assurance, dan emphaty terhadap kepuasan nasabah asuransi terhadap pelayanan PT. Prudential Life Assurance Kota Makassar adalah sebasar $65,8 \%$ dan sisanya sebesar $34,2 \%$ dijelaskan oleh variabel lainnya.

$R^{2}=0,658$ yang berarti besarnya pengaruh reliability, assurance, tangible, emphaty, dan responsiveness terhadap kepuasan nasabah asuransi terhadap pelayanan PT. Prudential Life Assurance Kota Makassar adalah sebasar $65,8 \%$ dan sisanya sebesar $34,2 \%$ dijelaskan oleh variabel lainnya seperti organisasi perusahaan dan kondisi internal $P T$. Prudential Life Assurance Kota Makassar

\section{KESIMPULAN}

Berdasarkan hasil perumusan kepuasan nasabah terhadap pelayanan yang diberikan oleh PT. Prudential Life Assurance Kota Makassar dan analisis regresi linier berganda, maka dapat disimpulkan sebagai berikut :

1. Nasabah merupakan peserta asuransi pada PT. Prudential Life Assurance Kota Makassar yang telah menjadi nasabah selama \pm 2 tahun. Karateristik nasabah terdiri dari empat bagian yaitu berdasarkan : a) jenis kelamin, dimana nasabah didominasi oleh perempuan sebanyak $68,9 \%$, b) umur dimana nasabah terbanyak adalah berumur 31 - 40 tahun sebanyak $37,93 \%$, c) pendidikan terakhir dimana nasabah terbanyak adalah nasabah yang berpendidikan sarjana sebanyak $3.33 \%$ dan d) pekerjaan dimana nasabah lebih banyak bekerja sebagai pengusaha yakni sebesar $44.83 \%$.

2. Kualitas pelayanan yang diberikan oleh PT. Prudential Life Assurance Kota Makassar diukur menggunakan Skala Likert dimana indikator pengukurannya adalah Sangat Setuju (SS), Setuju (S), Kurang Setuju (KS), Tidak Setuju (TS) dan Sangat Tidak Setuju (STS). Hasil pengukuran ini adalah a) pelayanan dalam bentuk fisik (tangible) bahwa nasabah memiliki kepuasan pelayanan agen yang senantiasa memperkenalkan dan menjelaskan fasilitas yang dimiliki perusahaan, b) nasabah memiliki kepuasan pelayanan terhadap kehandalan perusahaan (reliability) terutama dalam kemampuan agen untuk menyimpan identitas rahasia nasabah, c) nasabah memiliki kepuasan pelayanan tentang daya tanggap (responsiveness) perusahaan yang senantiasa memberikan informasi yang jelas dan tepat, d) nasabah memiliki kepuasan pelayanan tentang jaminan (assurances) yang diberikan oleh perusahaan bahwa setiap agen $P T$. Prudential Life Assurance Kota Makassar dapat diandalkan dan bersifat professional kepada nasabah/calon nasabah, e) nasabah memiliki kepuasan pelayanan tentang empati (emphaty) dimana agen tidak akan membeda-bedakan status sosial dalam pelayanan terhadap nasabah atau calon nasabah dan f) nasabah puas menjadi anggota asuransi dikarenakan nasabah merasa nyaman 
atas keramahan dan etika dari agen ketika melayani mereka.

3. Pengaruh kualitas pelayanan terhadap kepuasan nasabah berdasarkan hasil analisis regresi linier berganda diperoleh nilai $\mathrm{R}^{2}=$ 0,658 yang berarti terdapat pengaruh yang besar dari tangible, reliability, responsiveness, assurance, dan emphaty terhadap kepuasan nasabah asuransi terhadap pelayanan $P T$. Prudential Life Assurance Kota Makassar.

\section{REKOMENDASI KEBIJAKAN}

1. Perlu peningkatan pelatihan tentang pentingnya asuransi bagi masyarakat dalam perlindungan keselamatan diri dan pendidikan.

2. Pemerintah senantiasa mendukung perusahaan swasta seperti asuransi agar dapat berkembang dengan baik untuk peningkatan kesejahteraan masyarakat

\section{DAFTAR PUSTAKA}

Margono, 2004. Jenis dan Contoh Simple Random Sampling. PT. Gramedia. Jakarta.

Purwosutjipto, 2016. Pengertian Pokok Hukum Dagang Indonesia. PT. Raja Grafindo Persada. Jakarta.

Siyoto, 2015. Teknik Pengumpulan Data Penelitian Kualitatif. Press Gremindo. Yogyakarta.

Sugiyono, 2001. Prosedur Simple Random Sampling. PT. Gramedia. Jakarta.

www.prudential.co.id. Sekilas PT. Prudential Life Assurance. Buku Pegangan Asuransi Indonesia. Jakarta. 